\title{
AS OPCOOES MAIS COMUNS PARA QUEM DESEJA PRATICAR A ANTICONCEPÇÃO
}

Rosa Maria Godoy Serpa da Fonseca*

FONSECA, R.M.G.S. da As opções mais comuns para quem deseja praticar a anticoncepção. Rev. Esc. Enf. USP, São Paulo, 21(3):211-220, dez. 1987.

A autora apresenta um quadro-resumo dos principais métodos anticoncepcionais, destacando, para cada um deles: a efetividade, as vantagens, as desvantagens, os efeitos colaterais $e$ as recomendações para o uso correto. Espera que possa ser utilizado como guia pelos enfermeiros que, via de regra, são solicitados para orientar pessoas ou casais sobre este assunto.

UNITERMOS: Anticoncepção. Comportamento contraceptivo. Métodos anticoncepcionais.

O medo de uma gravidez não desejada pode prejudicar consideravelmente a vivência sexual de uma pessoa ou casal. Se for considerado que o uso do próprio corpo é um direito fundamental do ser humano, a busca do prazer sexual desvinculado da procriação é essencial para a prática libertadora da sexualidade.

Não são raras as vezes que, como profissionais, somos solicitados a orientar sobre anticoncepção. Porém, esse aconselhamento deve estar calcado numa postura filosófica de respeito à liberdade de escolha, liberdade esta que só é exercida quando a pessoa tem, pelo menos, conhecimento dos benefícios e riscos a que está exposta quando decide usar este ou aquele método para evitar filhos.

Com o objetivo de facilitar a visão global sobre os métodos anticoncepcionais mais disponiveis em nosso meio, foi elaborado um quadro-resumo, que, espera-se, possa ser utilizado como instrumento para facilitar a ação dos enfermeiros junto aos clientes/pacientes, numa situação de ajuda à opção anticoncepcional.

Cabe acrescentar que não se pretendeu esgotar a questão, mas apenas incentivar o aprofundamento dos que se interessarem pelo assunto.

Quando da elaboração do quadro acima citado, alguns pontos foram considerados, que são dados a seguir.

\footnotetext{
* Enfermeina. Professor-Assistente do Departamento de Enfermagem em Saúde Coletiva da Escola de Enfermagem da USP - disciplinas Saúde da Comunidade e Lnfermagem Preventiva e Comunithria.
} 
- Efetividade foi baseada em estudos realizados sob as mais diversas condições, o que torna impossível a comparação entre os dados numéricos obtidos, principalmente no que se refere aos métodos anticoncepcionais que não prescindem da ação do usuário. Nestes casos, a efetividade prática difere muito da teórica e é diretamente influenciada por fatores como a motivação da pessoa para o uso de determinado método, fase da vida em que se encontra, grau de escolaridade, estado marital etc. Para os métodos mais modernos a efetividade prática mais se aproxima da teórica; entretanto, também pode ser influenciada por fatores corno, por exemplo, a qualidade da assistência à saúde prestada.

- Quando se trataram os efeitos colaterais, pretendeu-se citar apenas aqueles a que está sujeito o usuário do método anticoncepcional em questão, e que estão diretamente relacionados a esta utilização. Às vezes, a prática de determinado método pode figurar entre a multicausalidade de um agravo à saúde. Por exemplo, a prática do coito interrompido pode figurar como coadjuvante numa condição de impotência sexual, embora não se encontre respaldo nenhum científico nisto; no entanto, a partir do momento em que o usuário faz esta relação, ela merece destaque.

- Quanto às vantagens e desvantagens, foram citadas aquelas comumente relacionadas como tal. Convém lembrar que um aspecto que se apresenta como vantajoso para uma pessoa pode ser altamente desfavorável para outra, ou pode assumir este ou aquele valor, de acordo com a situação em que se encontra a pessoa no momento em que optar por um ou outro mẻtodo anticoncepcional. Por estas razões, recomenda-se que, numa situação de aconselhamento em relação à anticoncepção, a enfermeira esteja alerta para outras necessidades e aspirações de seu cliente e não apenas as referentes ao seu aparelho reprodutor. Que a história de vida e a situação peculiar de cada um sejam os condicionantes da opção. 


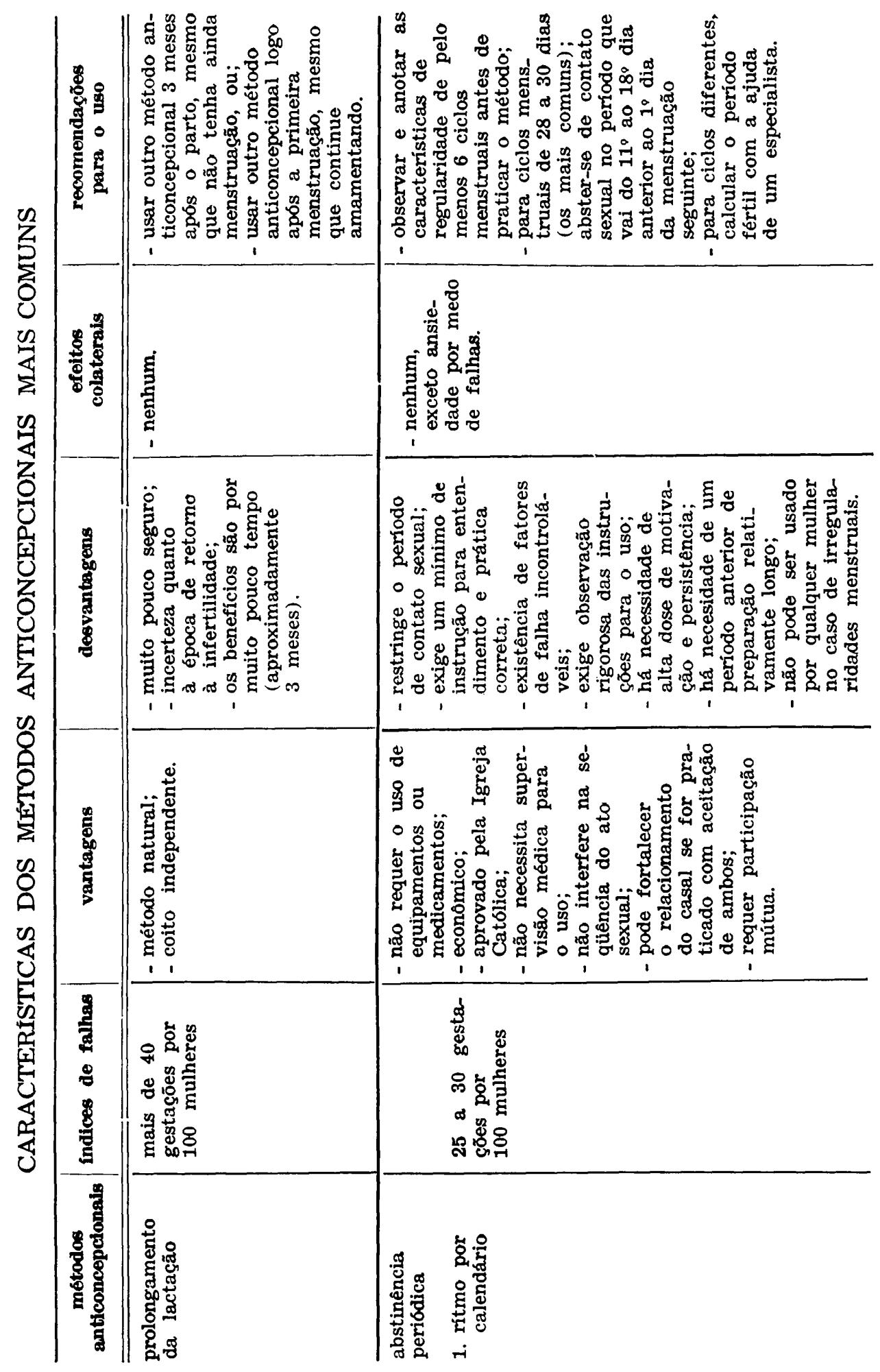




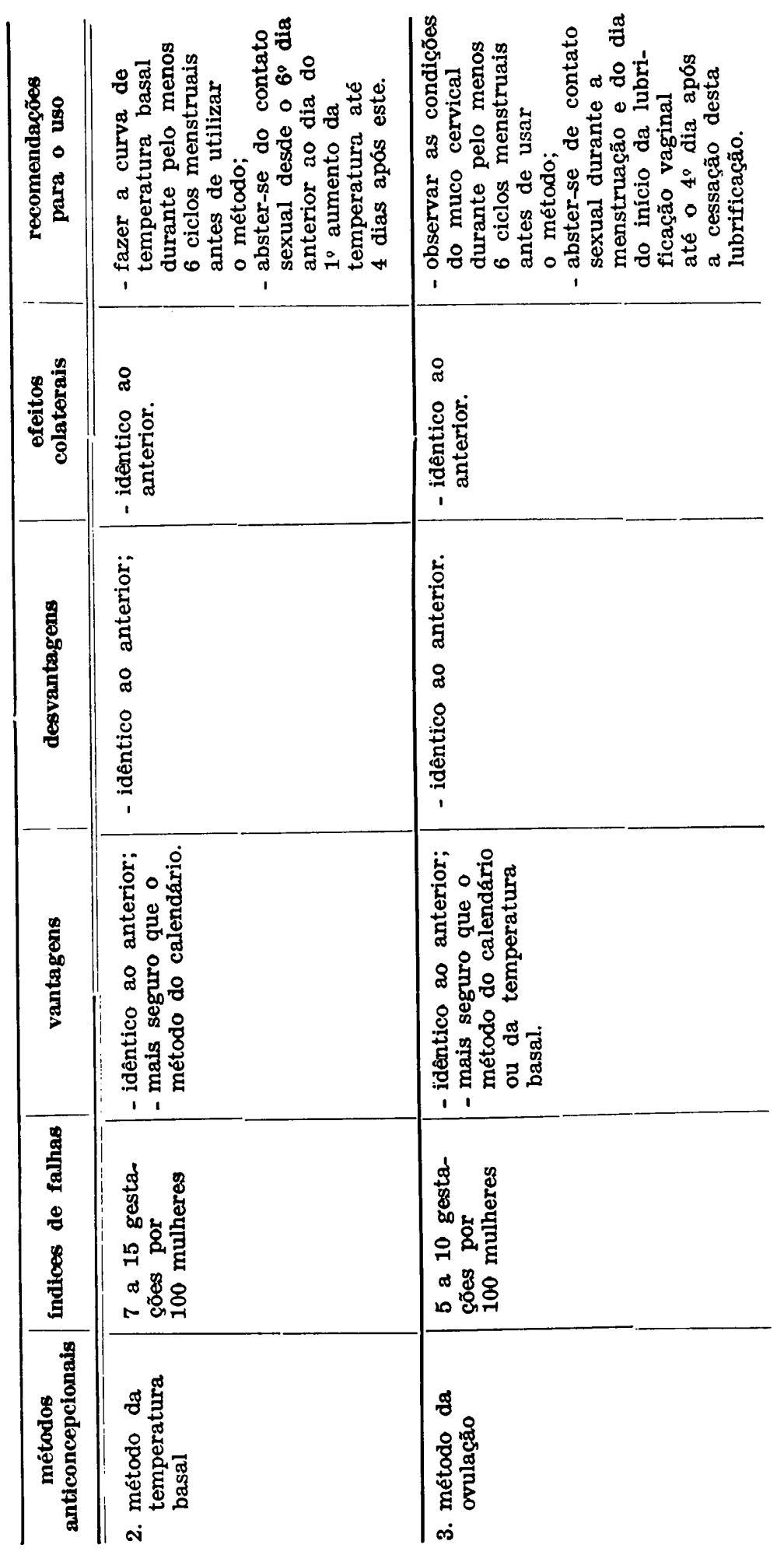




\begin{tabular}{|c|c|c|}
\hline 要。 & 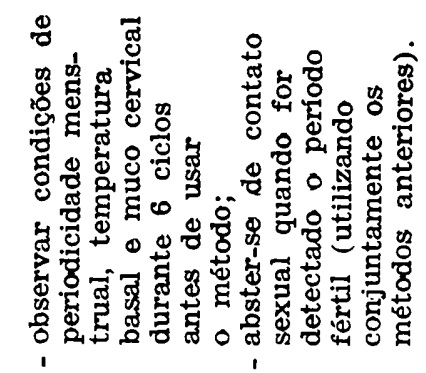 & 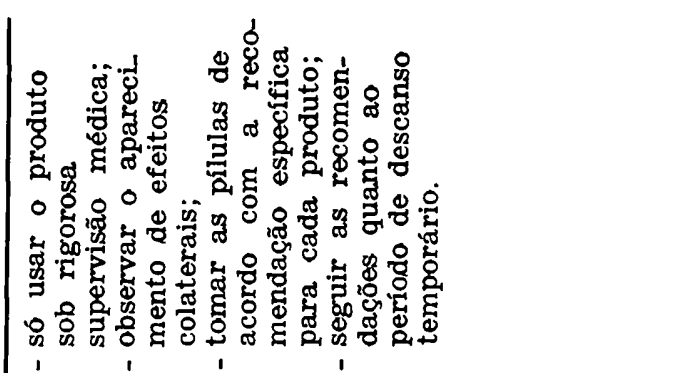 \\
\hline 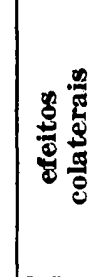 & 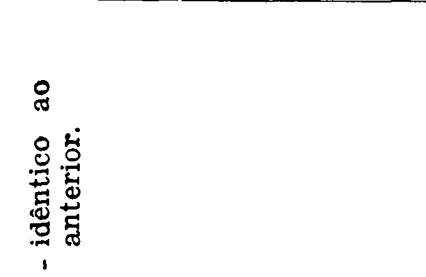 & 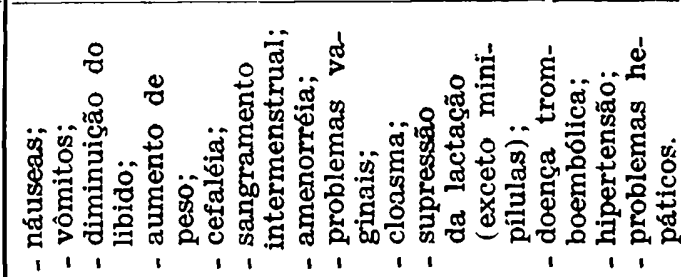 \\
\hline 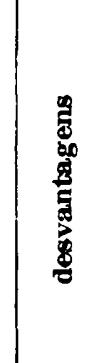 & 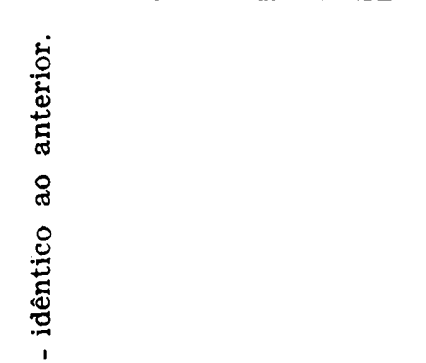 & 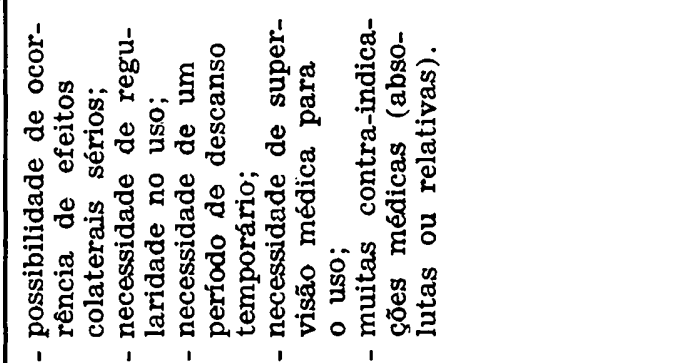 \\
\hline & 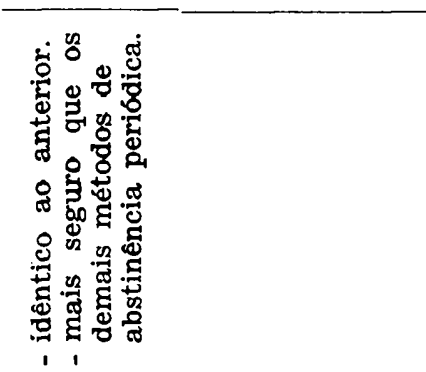 & 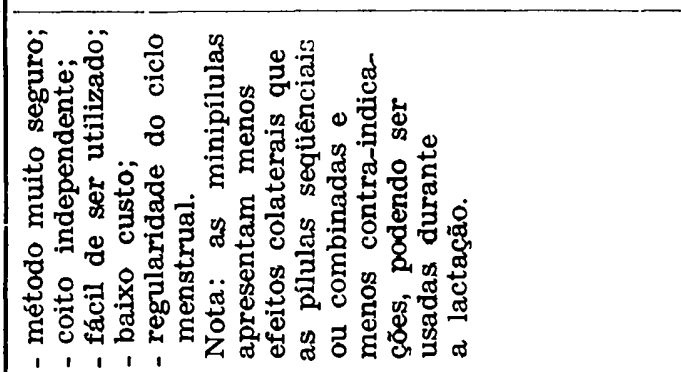 \\
\hline 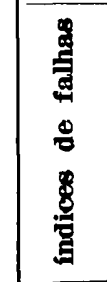 & 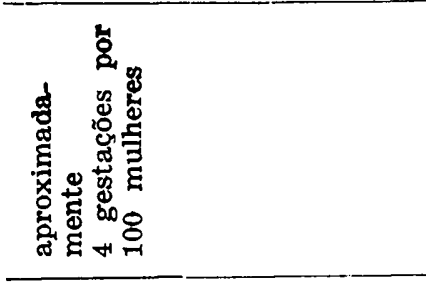 & 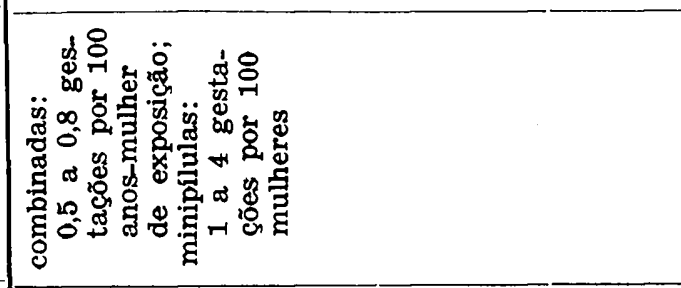 \\
\hline 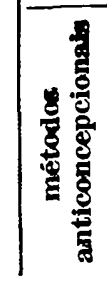 & 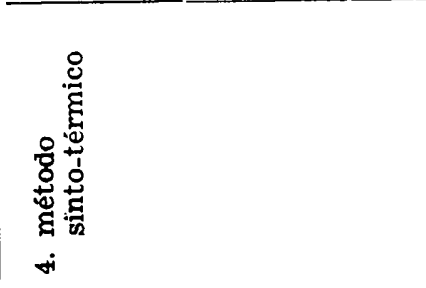 & 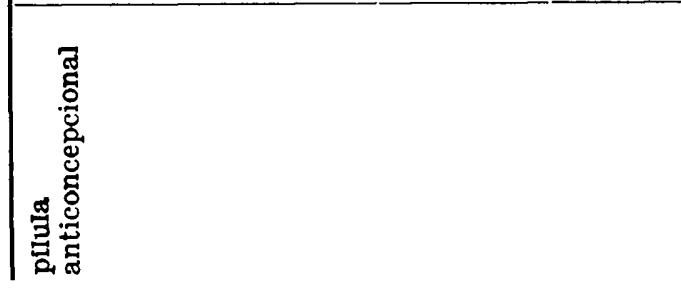 \\
\hline
\end{tabular}




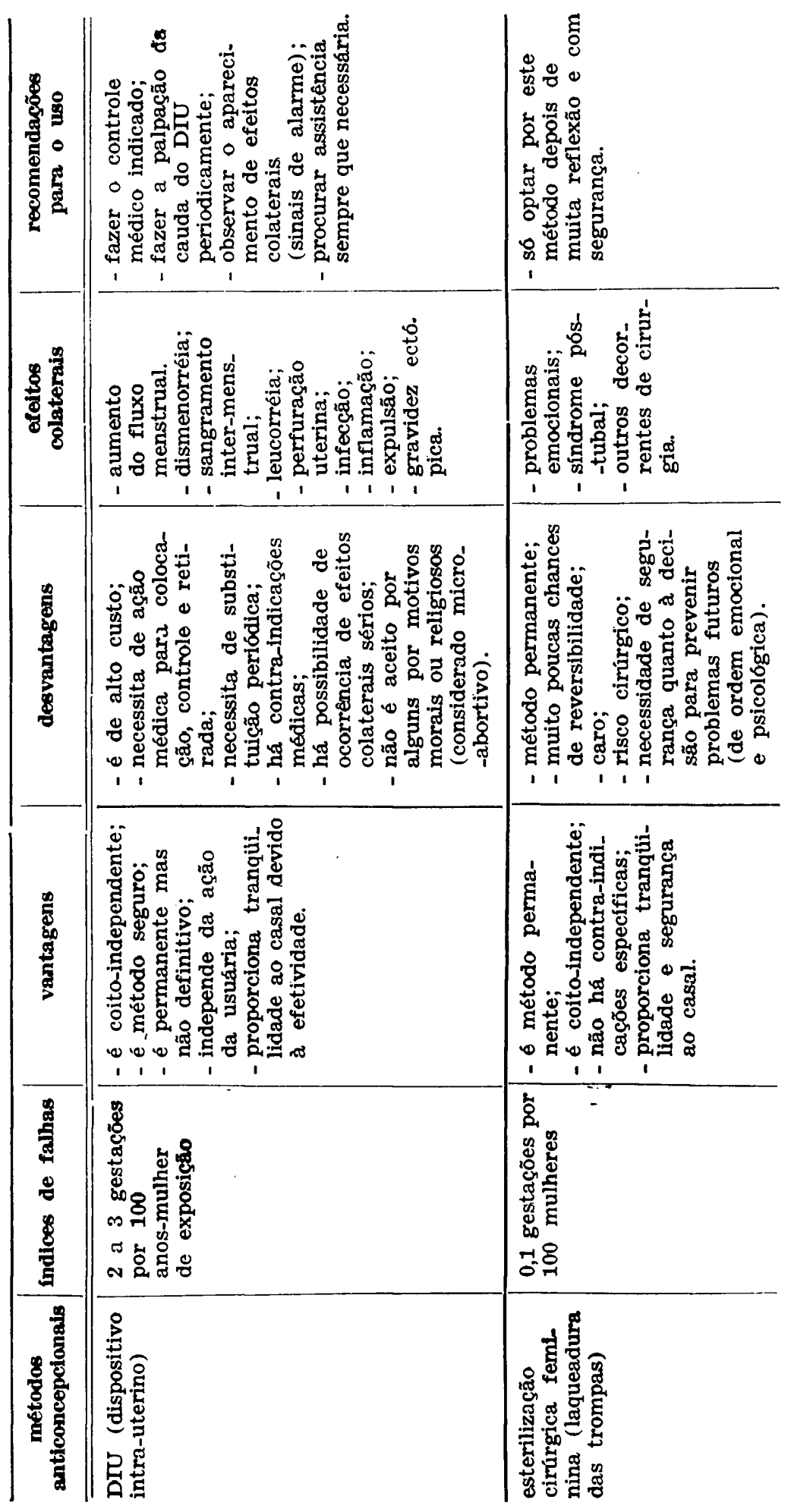




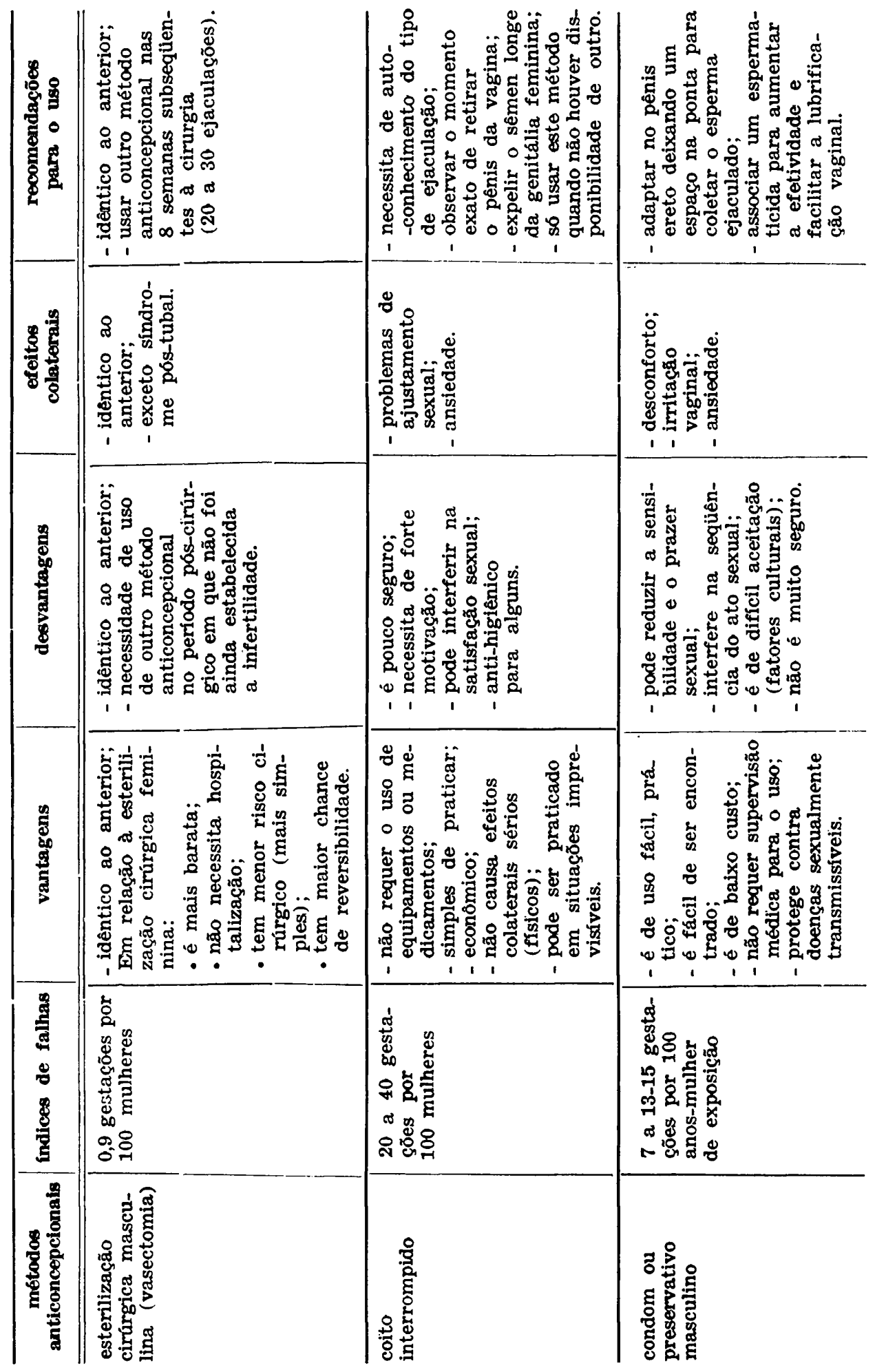




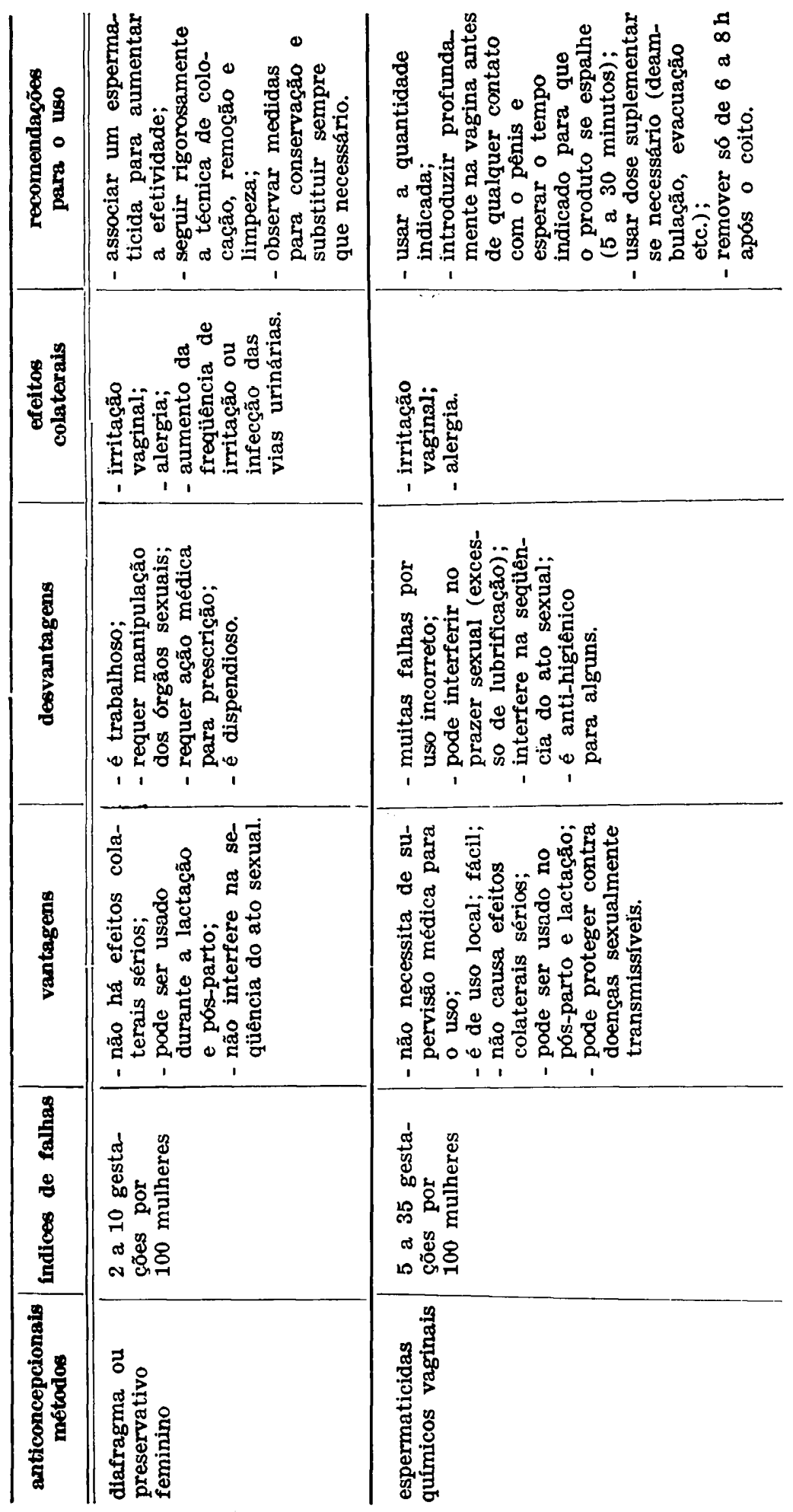




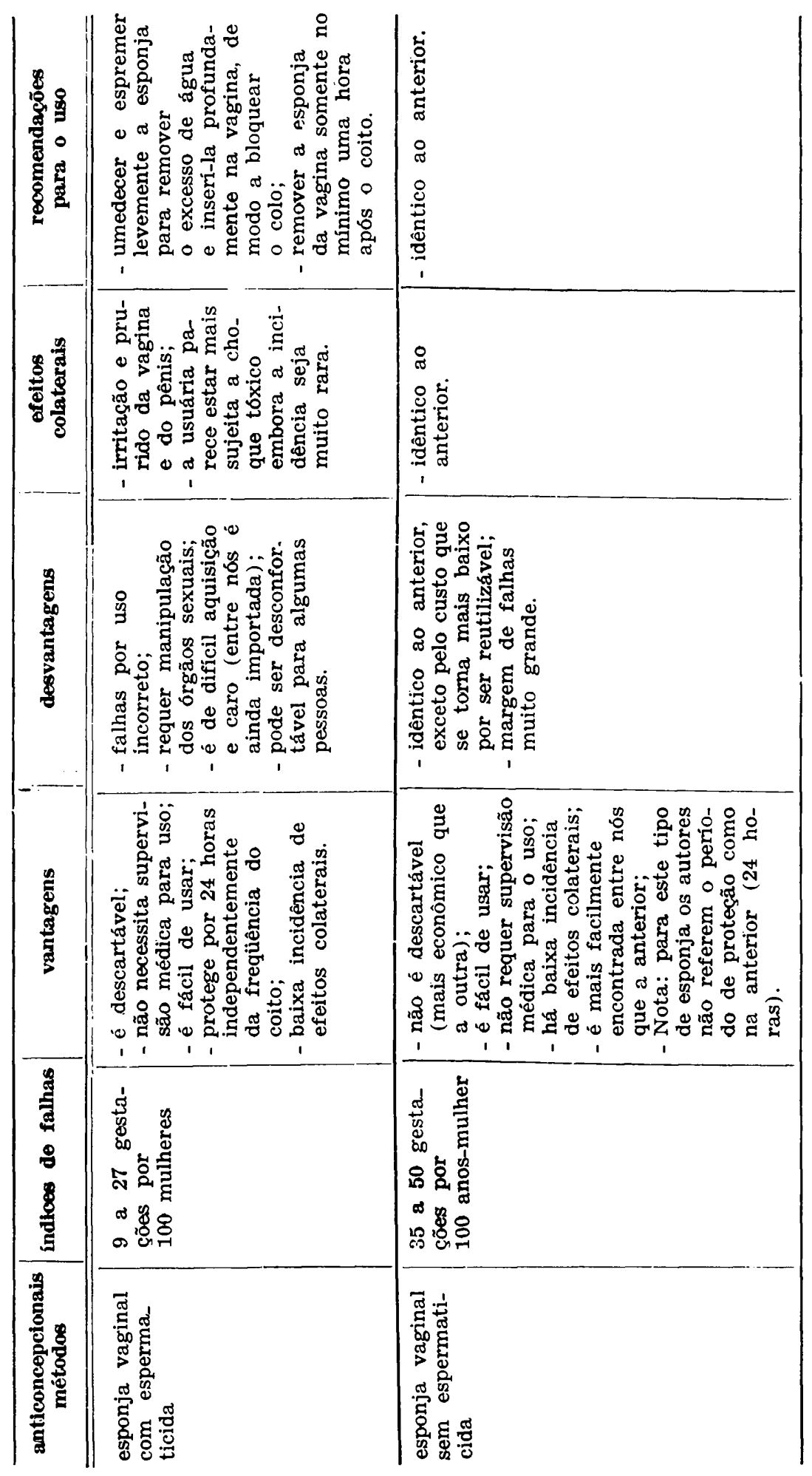


FONSECA, R.M.G.S. da The principal contraceptive methods. Rev. Esc. Enf. USP, São Paulo, $21(3): 211-220$, Dec. 1987.

The author presents a summary-table showing the principal contraceptive methods, highlighting each one for effectiveness, advantages, disadvantages, collateral effects and recommendations for correct use. The author hopes it will be used as a guide by the nurses who quite are, frequently, requested to orient persons and couples about this subject.

UNITERMS: Contraception. Contraception behavior. Contraceptive, methods.

\section{BIBLIOGRAFIA CONSULTADA}

ARAưJO, M.J.O. et alii. Métodos anticoncepcionais: o direito à informacăo. São Paulo, Fundação Carlos Chagas, 1986. 157p.

BARroso, C. Saúde da mulher. Folha de São Yaulo, 17 out. 1984.

FONSECA, R.M.G.S. Conhecimentos e opiniões de estudantes de enfermagem sobre planejamento familiar. São Paulo, 1981. 130p. (Dissertação de mestrado - Escola de Enfermagem da USP).

NAKAMURA, M.S. et alil. Avanços no controle da fertilidade. Sáo Paulo, Manole, $1979.172 p$. SHERRIS, J.D. Novidades em anticoncepcão vaginal. Washington, The George Washington University Medical Center, 1985. 35p. (Population Reports - série $H$, no 7).

WORTMAN, J, o diafragma e outras barreiras intra-vaginais: novo exame. Washington, The George Washington University Medical Center, 1976. 19p. (Population Reports série $\left.H, n^{\circ} 4\right)$.

Recebido para publicação em 9-3-87. (reapresentação)

Aprovado para publicação em 17-12-87. 